P-ISSN 2580 - 7781

E-ISSN 2615 - 3238

\title{
PERBEDAAN HASIL BELAJAR MATEMATIKA ANTARA PENGGUNAAN MODEL TEAM GAME TOURNAMENT (TGT) DENGAN METODE DISKUSI PADA SISWA KELAS 3 SD GUGUS 3 KECAMATAN KAPONGAN KABUPATEN SITUBONDO SEMESTER GANJIL TAHUN PELAJARAN 2019/2020
}

\section{DIFFERENCES IN LEARNING OUTCOMES MATHEMATICS BETWEEN THE USE OF THE TEAM MODEL TOURNAMENT GAME (TGT) WITH DISCUSSION METHOD IN CLASS 3 STUDENTS OF SD GUGUS 3, KAPONGAN DISTRICT, SITUBONDO DISTRICT, ODD SEMESTER OF STUDY YEAR 2019/2020}

\author{
Afif Amroellah \\ Fakultas Keguruan dan Ilmu Pendidikan, Universitas Abdurachman Saleh Situbondo \\ afif_amroellah@unars.ac.id
}

\begin{abstract}
ABSTRAK
Dilatarbelakangi oleh suatu fenomena bahwa matematika menjadi pelajaran yang ditakuti oleh siswa karena dianggap sulit. Padahal kesulitan yang dihadapi oleh siswa diakibatkan karena siswa tidak mampu memahami materi matematika secara baik. Kurangnya pemahaman siswa diakibatkan karena secara umum proses pembelajaran di kelas kurang menarik dan cenderung berpusat pada guru (teacher-centered). Selain itu, kurang tepatnya model pembelajaran yang diterapkan dengan materi yang diajarkan sangat berpengaruh pada minat belajar dan pemahaman siswa terhadap materi yang diajarkan sehingga akan berdampak pada hasil belajar yang dicapainya. Untuk meningkatkan hasil belajar siswa diperlukan pembelajaran yang menarik dan kebebasan dalam berpikir untuk memahami materi pelajaran sesuai kemampuan yang dimilikinya. Oleh karena itu guru harus mampu memposisikan diri dan menerapkan model pembelajaran yang menarik sesuai dengan materi yang diajarkan dan karakter siswa yang diajar. Tujuan dari penelitian ini adalah : Untuk mengetahui perbedaan hasil belajar matematika antara yang menggunakan Model TGT dengan Metode Diskusi Pada Siswa Kelas 3 Gugus 3 Kecamatan Kapongan Kabupaten Situbondo Semester Ganjil. Metode yang digunakan dalam penelitian ini meliputi pendekatan penelitian yang digunakan adalah penelitian kuantitatif, jenis penelitian yang digunakan adalah eksperimen semu, teknik sampling yang digunakan adalah sampel jenuh dengan jumlah populasi dan sampel yang sama yaitu 44 siswa yang berasal dari kelas III SDN 1 Seletreng dan III SDN 4 Seletreng, sumber data dalam penelitian ini berupa data primer yaitu siswa kelas III SDN 1 Seletreng dan III SDN 4 Seletreng selanjutnya data sekunder yang berasal dari hasil tes dan dokumentasi, instrumen yang digunakan dalam penelitian ini berupa pedoman tes, pedoman dokumentasi dan instrumen post test, dan teknik analisis data yang digunakan adalah uji-t. Dengan demikian dapat disimpulkan bahwa tidak ada pengaruh model team game tournament (TGT) dengan metode diskusi terhadap hasil belajar matematika materi pokok bilangan cacah pada siswa kelas III SD Gugus 3 Kecamatan Kapongan Kabupaten Situbondo semester ganjil tahun pelajaran 2019/2020. Adapun besar pengaruh pembelajaran model team game tournament (TGT) dengan metode diskusi terhadap hasil belajar matematika materi pokok bilangan cacah pada siswa kelas III SD Gugus 3 Kecamatan Kapongan semester ganjil tahun pelajaran 2019/2020 adalah 2,50\%.
\end{abstract}

Kata Kunci: Team Game Tournament (TGT) Dengan Metode Diskusi, Hasil Belajar, Matematika, Bilangan Cacah. 


\section{ABSTRACT}

It is motivated by a phenomenon that mathematics is a subject that is feared by students because it is considered difficult. Even though the difficulties faced by students are caused because students are not able to understand mathematics material well. The lack of understanding of students is caused by the fact that in general the learning process in the classroom is less attractive and tends to be teacher-centered. In addition, the inaccurate learning model that is applied to the material being taught greatly affects students' interest in learning and understanding of the material being taught so that it will have an impact on the learning outcomes they achieve. To improve student learning outcomes, interesting learning and freedom of thought are needed to understand the subject matter according to their abilities. Therefore, teachers must be able to position themselves and apply attractive learning models according to the material being taught and the character of the students being taught. The objectives of this study were: To determine differences in mathematics learning outcomes between those using the TGT Model and the Discussion Method for Class 3 Students of Cluster 3, Kapongan District, Situbondo District, Odd Semester. The method used in this study includes the research approach used is quantitative research, the type of research used is quasi-experimental, the sampling technique used is a saturated sample with the same population and sample, namely 44 students from class III SDN 1 Seletreng and III. SDN 4 Seletreng, the source of data in this research is primary data, namely students of class III SDN 1 Seletreng and III SDN 4 Seletreng, then secondary data derived from test results and documentation, the instruments used in this study were test guidelines, documentation guidelines and post instruments test, and the data analysis technique used is the t-test. Thus it can be concluded that there is no effect of the team game tournament (TGT) model with the discussion method on mathematics learning outcomes on the subject matter of whole numbers in grade III SD Gugus 3, Kapongan District, Situbondo District, odd semester of the 2019/2020 school year. As for the great influence of learning the team game tournament (TGT) model with the discussion method on learning outcomes of mathematics in the subject matter of whole numbers in grade III SD Gugus 3, Kapongan District, Situbondo District, odd semester of the 2019/2020 academic year is 2.50\%.

Keywords: Team Game Tournament (TGT) with Discussion Method, Learning Outcomes, Mathematics, Total Numbers.

\section{PENDAHULUAN}

Kualitas pendidikan dapat diketahui dari dua hal, yaitu : kualitas proses dan produk (Sudjana, 2002 : 35). Suatu pendidikan dikatakan berkualitas apabila proses belajar mengajar (PBM) dapat berlangsung secara efektif dan peserta didik mengalami proses pembelajaran yang bermakna. Pendidikan disebut berkualitas apabila peserta didik menunjukkan tingkat penguasaan yang tinggi terhadap tugastugas belajar sesuai dengan sasaran dan tujuan pendidikan. Hal ini dilihat pada hasil belajar yang dinyatakan dalam proses akademik.

Pendidikan dikatakan berkualitas apabila terjadi penyelenggaraan pembelajaran yang efektif dan efisien dengan melibatkan semua komponenkomponen pendidikan, seperti mencakup tujuan pengajaran, guru dan peserta 
P-ISSN 2580 - 7781

E-ISSN 2615 - 3238

didik, bahan pelajaran, strategi/metode belajar mengajar, alat dan sumber pelajaran serta evaluasi (Sugito, 2004 : 3). Komponen- komponen tersebut dilibatkan secara langsung tanpa menonjolkan salah satu komponen saja, akan tetapi komponen tersebut diberdayakan secara bersama-sama.

Untuk bidang pendidikan matematika, rencana Pemerintah untuk mengadakan perubahan dari Kurikulum 2006 ke Kurikulum 2013 tersebut adalah sejalan dengan berbagai seruan perubahan yang telah dikemukakan oleh berbagai pihak dalam dunia pendidikan matematika internasional, misalnya oleh National Council of Teachers of Mathematics (NCTM), suatu organisasi profesi pendidikan matematika di Amerika Serikat yang sangat berpengaruh, yang sejak tahun 1980an telah menyerukan diadakannya perombakan secara menyeluruh terhadap praktek pembelajaran matematika di banyak negara, termasuk di Amerika Serikat sendiri, yang antara lain mendorong agar praktek pembelajaran matematika beralih dari pembelajaran yang bersifat teacher-centered ke pembelajaran yang bersifat student-centered, dan mengubah para siswa yang sebelumnya merupakan pembelajar yang pasif (passive learners) menjadi siswa merupakan pembelajar yang aktif (active learners) (NCTM, 1989, 2000).

Berdasarkan masalah tersebut, peneliti mencoba mengkaji suatu alternatif menggunakan model pembelajaran Team Game Tournament (TGT) dengan metode diskusi karena kedua model pembelajaran ini model pembelajaran berkelompok sehingga memudahkan siswa untuk memahami materi yang di berikan oleh guru. Model pembelajaran efektif dalam proses pembelajaran matematika antara lain adalah yang dapat menumbuhkan kreatifitas peserta didik. Peserta didik SD senang dalam bentuk permainan dan pertandingan, sehingga guru dapat menggunakan model pembelajaran yang mempunyai unsur permainan dan pertandingan. Model pembelajaran Team Game Tournament (TGT) salah satu alternatif yang dapat digunakan guru SD, karena model pembelajaran ini sesuai dengan karakter peserta didik SD yang senang dengan permainan dan pertandingan. Model pembelajaran TGT juga memiliki dinamika motivasi yang tinggi sehingga diharapkan dapat meningkatkan motivasi belajar siswa terhadap hasil belajarnya. Hasil belajar atau achievement merupakan realisasi atau 
P-ISSN $2580-7781$

E-ISSN 2615 - 3238

pemekaran dari kecakapan-kecakapan potensial atau kapasitas yang dimiliki seseorang (Sukmadinata $2005: 102)$.

Menurut Anita Lie (2002 : 58) Model Pembelajaran Team Game Tournament (TGT) adalah salah satu pembelajaran kooperatif yang menempatkan peserta didik dalam kelompok-kelompok belajar yang beranggotakan 5 sampai 6 orang peserta didik yang memiliki kemampuan, jenis kelamin dan suku kata atau ras yang berbeda. Guru menyajikan materi dan peserta didik bekerja dalam kelompok mereka masing-masing.

Metode Diskusi menurut Milan Rianto (2006 : 55) adalah merupakan cara penyajian materi pelajaran dengan tukar menukar pendapat untuk mencari pemecahan permasalahan tentang suatu topik tertentu. Melalui diskusi peserta didik termotivasi untuk belajar secara aktif dan saling mengembangkan pendapatnya sendiri dalam memecahkan suatu topik permasalahan.

Pada umumnya guru mengajar hanya menyampaikan apa yang ada dibuku paket dan kurang mengkomodasi kemampuan berfikir siswanya. Sehingga guru cenderung tidak mengajar secara bermakna. Guru tidak memberikan kesempatan pada siswanya untuk mengkontruksi pengetahuan matematika yang akan menjadi milik siswa sendiri. Guru cenderung memaksakan cara berfikir siswa dengan cara berfikir yang dimiliki gurunya.

Pembelajaran yang dilaksanakan di Gugus 3 Kecamatan Kapongan pada saat ini masih menggunakan pembelajaran konvensional, dimana guru menjadi pusat perhatian para siswa. Inilah penyebab kejenuhan dan tidak berkembangnya cara berpikir siswa. Sampai saat ini matematika dan pembelajarannya selalu mendapat keluhan dan kritik dari berbagai pihak, baik siswa, orang tua, masyarakat, pengamat pendidikan bahkan dari guru matematika itu sendiri.

Bukti-bukti empiris di lapangan menunjukkan bahwa masih banyak siswa yang mengalami kesulitan dalam belajar matematika, mulai tingkat dasar sampai perguruan tinggi. Di SDN Gugus 3 Kecamatan Kapongan masih banyak ditemukan siswa yang masih kesulitan dalam belajar matematika, itu karena metode serta pendekatan yang digunakan dalam proses pembelajaran masih monoton dan kurang berkembang. Berdasaarkan hasil observasi awal, terungkap 
P-ISSN 2580 - 7781

E-ISSN 2615 - 3238

bahwa siswa masih kurang antusias dalam belajar dan hasil belajar siswa pada pokok bahasan bilangan cacah. Nilai matematika siswa kelas 3 Gugus 3 Kecamatan Kapongan tahun pelajaran 2019-2020 sebagian besar masih dibawah KKM. Sementara ketuntasan klasikal siswa juga masih dibawah 85\%. Penelitian ini bertujuan untuk mengetahui perbedaan hasil belajar matematika antara yang menggunakan Model TGT dengan Metode Diskusi Pada Siswa Kelas 3 Gugus 3 Kecamatan Kapongan Semester Ganjil.

\section{METODE PENELITIAN}

Penelitian ini dilaksanakan di Sekolah Dasar Gugus 3 Kecamatan Kapongan Kabupaten Situbondo Tahun Pelajaran 2019/2020. Peneliti memilih tempat ini karena untuk mempermudah kerjasama antar peneliti, pihak sekolah, objek yang diteliti serta untuk menghemat waktu dan biaya karena tempat penelitian ini dekat dengan rumah peneliti. Rencana penelitian ini akan dilaksanakan pada Semester Ganjil Tahun Pelajaran 2019-2020 dimulai bulan Juli sampai Agustus 2019.

Dalam penelitian ini, peneliti menggunakan beberapa metode pengumpulan data, antara lain :

a. Metode Tes

Tes menurut Anas Sudijono (2005: 67) adalah suatu cara yang dapat dipergunakan dalam rangka pengukuran dan penilaian di bidang pendidikan, yang berbentuk pemberian tugas atau serangkaian tugas yang harus dikerjakan oleh testee, sehingga dapat dihasilkan nilai yang melambangkan tingkah laku yang dapat dibandingkan dengan nilai-nilai yang dicapai oleh testee lainnya, atau dibandingkan dengan nilai standar tertentu. Dalam penelitian ini, metode tes digunakan untuk mengetahui hasil belajar matematika pada pokok bahasan bilangan cacah pada siswa kelas 3 SD Gugus 3 kecamatan Kapongan tahun ajaran 2015/2016.

b. Metode Dokumentasi

Menurut Suharsimi Arikunto (2006 : 158) dokumentasi berasal dari kata dokumen yang artinya barang tertulis. Di dalam melaksanakan metode dokumentasi, peneliti menyelidiki benda-benda tertulis seperti buku-buku, majalah, dokumen, peraturan-peraturan, notulen rapat, catatan 
P-ISSN 2580 - 7781

E-ISSN 2615 - 3238

harian dan sebagainya. Metode ini digunakan untuk memperoleh data nilai raport siswa, data guru, data jumlah siswa, dan data nama-nama siswa. Pada metode dokumentasi tersebut memakai prostes.

Dalam penelitian ini, peneliti menggunakan teknik analisis data kuantitatif. Adapun data kuantitatif ini di analisis menggunakan analisis statistik. Analisis statistik yang digunakan adalah analisis statistik deskriptif dan analisis statistik inferensial. Analisis statistik deskriptif, mendeskripsikan atau memberikan gambaran data dalam bentuk tabel, grafik, histogram dari nilai rata-rata agar lain dengan mudah memperoleh gambaran mengenai sifat (karateristik) objek dari data tersebut. Sedangkan analisis inferensial untuk pengujian hipotesis. Sebelum pengujian hipotesis dilakukan uji prasyarat pembuktian hipotesis, yaitu sebagai berikut :

a. Uji Normalitas

Uji normalitas yang paling sederhana menurut Agus Irianto (2007 : 272) adalah membuat grafik distribusi frekuensi atas skor yang ada. Untuk menguji normalitas data menurut Agus Eko Sujianto (2009 : 78) dapat menggunakan uji Kolmogorov-Smirnov dengan ketentuan jika Asymp. Sign > 0,05 maka data berdistribusi normal. Uji normalitas dimaksudkan untuk mengetahui apakah data hasil penelitian berasal dari populasi yang normal atau tidak. Jika data hasil penelitian berasal dari distribusi normal maka dilanjutkan pada uji homogenitas.

b. Uji Homogenitas

Uji homogenitas dilakukan untuk memastikan apakah asumsi homogenitas pada masing-masing kategori data sudah terpenuhi ataukah belum. Apabila homogenitas terpenuhi maka peneliti dapat melakukan pada tahap analisa data lanjutan, apabila tidak maka harus ada pembetulaan-pembetulan metodologis.

Pengujian homogenitas antara kelompok menggunakan uji Harley. Uji Harley merupakan uji homogenitas variansi yang sangat sederhana karena kita cukup membandingkan variansi terbesar dengan variansi terkecil yang dilambangkan dengan rumus : 


$$
F_{\text {max }}=\frac{\text { variasi terbesar }}{\text { variasi terkecil }}
$$

Hasil hitung $F_{\max }$ dibandingkan dengan $F_{\max }$ tabel, adapun kriteria pengujianya sebagai berikut :

$$
\begin{gathered}
\text { Terima } H_{0} \text { jika } F(\max )_{\text {hitung }} \leq F(\max )_{\text {tabel }} \\
\text { Tolak } H_{0} \text { jika } F(\max )_{\text {hit } \text { 预 }_{\text {g }}>F(\max )_{\text {tabel }}}
\end{gathered}
$$

Adapun $H_{\mathrm{o}}$ menyatakan variansi homogen, sedangkan $H_{1}$ menyatakan variansi tidak homogen. Uji homogenitas variansi dengan rumus Harley bisa digunakan jika jumlah sampel antar kelompok sama.

c. Uji Hipotesis

1) $H_{o}=\left(?_{1}=?_{2}\right)$ ada perbedaan yang signifikan hasil belajar matematika antara model pembelajaran TGT dengan Motode Diskusi pada siswa kelas 3 SD Gugus 3 Kecamatan Kapongan.

2) $H_{a}=\left(?_{1} \neq ?_{2}\right)$ tidak ada perbedaan yang signifikan hasil belajar matematika antara model pembelajaran TGT dengan Metode Diskusi pada siswa kelas 3 SD Gugus 3 Kecamatan Kapongan.

Keterangan :

$?_{1}=$ rata-rata hasil belajar siswa dengan model pembelajaran Team Game Tournament (TGT) (pertemuan eksperimen ke-1).

$?_{2}=$ rata-rata hasil belajar siswa dengan pembelajaran Metode Diskusi (pertemuan eksperimen ke-2).

Kriteria pengujian : jika thitung $\leq \mathrm{t}$ tabel ( maka $H_{o}$ diterima)

Setelah pengujian prasyarat tersebut terpenuhi, selanjutnya peneliti melakukan analisis data lanjutan. Menurut Sabana (2005 : 168) analisis data yang digunakan dalam penelitian ini adalah t-test atau biasa disebut dengan uji-t. Uji-t adalah tes statistik yang dapat dipakai untuk menguji perbedaan atau kesamaan dua kondisi/ perlakuan atau dua kelompok berbeda dengan prinsip membandingkan rata-rata (mean) kedua kelompok/ prilaku itu. 
P-ISSN 2580 - 7781

E-ISSN 2615 - 3238

Rumus yang digunakan adalah rumus $t$-test sebagai berikut :

$$
t=\frac{\bar{x}_{1}-\bar{x}_{2}}{\sqrt{\left(\frac{S D_{12}}{N_{1}}\right)+\left(\frac{S D_{2^{2}}}{N_{2}}\right)}}
$$

Keterangan :

$t \quad=$ angka atau koefisien derajad perbedaan mean kedua kelompok.

$\bar{x}_{1}=$ mean pada distribusi sampel 1

$\bar{x}_{2}=$ mean pada distribusi sampel 2

$S D_{1^{2}}=$ nilai varian pada distribusi sampel 1

$S D_{2^{2}}=$ nilai varian pada distribusi sampel 2

$N_{1} \quad=$ jumlah individu pada sampel 1

$N_{2} \quad=$ jumlah individu pada sampel 2

Apabila disederhanakan rumus $t$-test tersebut akan menjadi :

$$
t-t e s t=\frac{\bar{x}_{1}-\bar{x}_{2}}{S D_{b m}}
$$

Dimana $S D_{b m}$ adalah standar kesalahan perbedaan mean yang diperoleh melalui rumus : $S D_{b m}=\sqrt{\left[\frac{S D_{1}^{2}}{N_{1}-1}\right]+\left[\frac{S D_{2}^{2}}{N_{2}-1}\right]}$

\section{HASIL PENELITIAN DAN PEMBAHASAN}

Untuk mengetahui seberapa jauh perbedaan hasil belajar matematika antara model pembelajaran TGT dan motode diskusi pada siswa kelas III, perlu diuji signifikansinya dengan menggunakan analisis uji beda teknik t-test. T-test dilakukan dengan menggunakan sampel dari 2 kelas kontrol dan kelas eksperimen. Berikut adalah langkah-langkah perhitungan $t$-test untuk $x$ (model pembelajaran TGT dan metode diskusi).

Menghitung rata-rata nilai :

$$
\begin{aligned}
& X_{1}=\text { Kelas Kontrol } \\
& X_{2}=\text { Kelas Eksperimen }
\end{aligned}
$$


P-ISSN 2580 - 7781

E-ISSN 2615 - 3238

$$
\begin{gathered}
\bar{x}_{1}=\frac{\sum x_{1}}{N_{1}} \\
=\frac{1988}{25}=79.52 \\
\bar{x}_{2}=\frac{\sum x_{2}}{N_{2}} \\
=\frac{1474}{19}=77.58
\end{gathered}
$$

Menghitung standar deviasi :

$$
\begin{gathered}
S D_{1}^{2}=\frac{\sum x_{1}^{2}}{N_{1}}-\left(\bar{x}_{1}\right)^{2} \\
=\frac{159.658}{25}-6323.43 \\
=6386.32-6323.43=62.89 \\
S D_{2}^{2}=\frac{\sum x_{2}^{2}}{N_{2}}-\left(\bar{x}_{2}\right)^{2} \\
=\frac{115604}{19}-6018.49 \\
=6084.42-6018.49=65.93
\end{gathered}
$$

Maka besarnya t-test dapat dihitung sebagai berikut :

$$
\begin{aligned}
t-t e s t & =\frac{\bar{X}_{1}-\bar{X}_{2}}{\sqrt{\left(\frac{S D_{1}^{2}}{N_{1}-1}\right)+\left(\frac{S D_{2}^{2}}{N_{2}-1}\right)}} \\
& =\frac{79.52-77.58}{\sqrt{\left(\frac{62.89}{25-1}\right)+\left(\frac{65.93}{19-1}\right)}} \\
& =\frac{1.94}{\sqrt{\left(\frac{62.89}{24}\right)+\left(\frac{65.93}{18}\right)}} \\
& =\frac{1.94}{\sqrt{(2.62)+(3.663)}} \\
& =\frac{1.94}{\sqrt{6.283}}
\end{aligned}
$$


P-ISSN 2580 - 7781

E-ISSN 2615 - 3238

$$
\begin{aligned}
& =\frac{1.94}{2.507} \\
& =0.774
\end{aligned}
$$

Membandingkan $t_{\text {hitung }}$ dengan $t_{\text {tabel }}$.

$$
\mathrm{db}=\mathrm{N}-2=44-2=42
$$

Karena pada tabel nilai-nilai t, db 42 berada ditengah-tengah antara db 40140, maka dapat dihitung, pada taraf signifikansi 5\% nilai $\mathrm{t}_{\text {tabel }}$ sebesar 2.0181. Kriteria pengujiannya yaitu di terima $\mathrm{H}_{\mathrm{o}}$ jika $\mathrm{t}_{\text {hitung }}<\mathrm{t}_{\text {tabel }}$ dan di tolak jika $\mathrm{t}_{\text {hitung }}>$ $\mathrm{t}_{\text {tebel }}$. Setelah dilakukan penghitungan dengan menggunakan uji t-test, diperoleh bahwa $t_{\text {tabel }}<t_{\text {hitung }}$ yaitu $2.0181>1.050$. Sehingga dapat ditarik kesimpulan menolak $\mathrm{H}_{\mathrm{o}}$ yang artinya ada perbedaan yang signifikan hasil belajar matematika pokok bahasan bilangan cacah antara model pembelajaran TGT dengan metode diskusi pada siswa kelas III SD Gugus 3 Kecamatan Kapongan.

Tabel 1. Analisis Uji Kesamaan Dua Varian

\begin{tabular}{|cc|c|c|c|c|c|}
\hline \multicolumn{2}{|c|}{ Kelas } & Mean & $\mathbf{N}$ & $\mathbf{f}_{\text {hitung }}$ & $\mathbf{f}_{\text {tabel }}$ & Kriteria \\
odel TGT & $\mathrm{M}$ & 9,52 & 5 &, 050 &, 0181 & arian Sama \\
\hline \multirow{2}{*}{ etode Diskusi } & $\mathrm{M}$ & 7,58 & 9 &, 050 &, 0181 & arian Sama \\
\hline
\end{tabular}

Sedangkan untuk mengetahui besarnya pengaruh penerapan model pembelajaran TGT dengan metode diskusi terhadap hasil belajar matematika siswa SD kelas 3 Gugus 3 Kecamatan Kapongan Semester Ganjil Tahun Pelajaran 2015/2016 dapat diketahui melalui penghitungan sebagai berikut :

$$
\begin{gathered}
Y=\frac{\bar{X}_{1}-\bar{X}_{2}}{\bar{X}_{2}} \times 100 \% \\
=\frac{79.52-77.58}{77.58} \times 100 \% \\
=\frac{1.94}{77.58} \times 100 \% \\
=0.02501 \times 100 \% \\
=2.50 \%
\end{gathered}
$$


P-ISSN 2580 - 7781

E-ISSN 2615 - 3238

Berdasarkan perhitungan tersebut dapat disimpulkan bahwa besarnya pengaruh penerapan model pembelajaran TGT dengan metode diskusi terhadap hasil belajar matematika siswa SD kelas 3 Gugus 3 Kecamatan Kapongan Semester Ganjil Tahun Pelajaran 2019/2020 adalah $2.50 \%$.

Dari data diatas dapat disimpulkan bahwa interpretasi besarnya pengaruh model pembelajaran tersebut adalah sangat rendah. Hal ini dapat dilihat pada kriteria persentasi besarnya pengaruh sebagai berikut :

$$
\begin{array}{ll}
0 \%-20 \% & : \text { Sangat Rendah } \\
21 \%-40 \% & : \text { Rendah } \\
41 \%-70 \% & : \text { Sedang } \\
71 \%-90 \% & : \text { Tinggi } \\
91 \%-100 \% & \text { : Sangat Tinggi }
\end{array}
$$

Berdasarkan dari analisis data dan pengujian hipotesis mengenai perbedaan hasil belajar matematika siswa antara model pembelajaran Team Game Tournament (TGT) dengan metode diskusi pada kelas III SDN Gugus 3 Kecamatan Kapongan didapatkan hasil sebagai berikut:

1. Tidak ada perbedaan yang signifikan hasil belajar matematika siswa antara model pembelajaran Team Game Tournament (TGT) dengan metode diskusi.

2. Besarnya perbedaan hasil belajar matematika siswa antara model pembelajaran Team Game Tournament (TGT) dengan metode diskusi adalah $2.50 \%$.

\section{KESIMPULAN}

Berdasarkan rumusan masalah dan hipotesis penelitian yang diajukan, serta hasil penelitian yang didasarkan pada analisis data dan pengujian hipotesis, maka kesimpulan yang dapat dikemukakan dalam penelitian ini adalah :

1. Ada perbedaan yang signifikan hasil belajar matematika antara model pembelajaran TGT dengan metode diskusi pada siswa SDN Gugus 3 Kecamatan Kapongan. Hal ini ditunjukkan oleh nilai $t_{\text {hitung }}=0,776$, sedangkan pada taraf signifikasi 5\% adalah 2,0181. Dengan demikian hipotesis pada penelitian ini tidak dapat diterima yang menyatakan bahwa tidak ada perbedaan yang signifikan antara model pembelajaran TGT dengan metode diskusi pada siswa SDN Gugus 3 Kecamtan Kapongan. 
P-ISSN 2580 - 7781

E-ISSN 2615 - 3238

2. Adapun besarnya perbedaan hasil belajar matematika antara yang menggunakan model pembelajaran TGT dengan metode diskusi adalah 2,50\%.

\section{DAFTAR PUSTAKA}

Agus Eko Sujianto. 2009. Aplikasi Statistik dengan SPSS 16.0. Jakarta: PT. Prestasi Pustaka

Agus Irianto. (2007). Statistika Konsep Dasar dan Aplikasinya. Jakarta: Kencana.

Anas Sudijono. 2005. Pengantar Evaluasi Pendidikan. Jakarta: Paja Grafindo Persada.

Arikunto, S. 2006. Metode Penelitian Kualitatif. Jakarta: Bumi Aksara

Milan Rianto, Model Pembelajaran Terpadu Dlam Teori dan Praktek. Jakarta, Prestasi Pustaka. (2006 : 55)

Nana Syaodih Sukmadinata. 2005. Metode Penelitian Pendidikan. Bandung: Remaja Rosda Karya.

Sabana. 2005. Statistik Pendidikan, Bandung: Pustaka Setia

Sudjana, Nana. 2002. Dasar-dasar Proses Belajar Mengajar. Bandung: Sinar Baru Algensindo 